\title{
Importance of Corporate Governance for Energy in Sustainable Development and Evaluation with Quantitative SWOT Analysis
}

\author{
B. TUGRUL ${ }^{a, *}$ AND S. CIMEN ${ }^{b}$ \\ ${ }^{a}$ Istanbul Technical University, Nuclear Researches Division, Istanbul, Turkey \\ ${ }^{b}$ Ministry of Energy and Natural Resources, Ankara, Turkey
}

\begin{abstract}
Human development goals should be meeting with sustaining the ability of natural systems to continue to provide the natural resources and ecosystem services upon which the economy and society that is "Sustainable Development". For this aim, corporate governance and related activities are important that broadly refers to the mechanisms, processes and relations by which corporations are controlled and directed. SWOT analysis is a method that considers Strengths and Weaknesses along with the Opportunities and Threats that exist in the incorporated body environment. Internal and external factors generate ideas about how their incorporated body might become more successful by using SWOT analysis. For logic comparison of these ideas, analytic hierarchy process was applied for SWOT analysis and important values of them were determined and evaluated rationally.
\end{abstract}

DOI: 10.12693/APhysPolA.130.87

PACS/topics: 92.70.Mn, 92.70.-j

\section{Introduction}

Energy growth is directly linked to welfare and prosperity of the countries in all over the world. Therefore, energy has a pivotal role in every society, touching upon all aspects of life and creating the welfare of people and consolidates the country's standing among the others. Usage and management of energy is an important measuring criterion for the countries in the view of evaluation for developing statute in the world, but in many case it is not appropriate to sustainable development.

Energy management is important and it has governmental and private factors in complexity. Therefore, reaching out the energy resources or producing of it is an important target for all over the world. Access to the energy and/or energy resources, in particular providing energy sources in large scale, has become an indispensable requirement for the countries and it is affected on global warming [1-4].

Environmental sustainability is the process of making sure current processes of interaction with the environment. Therefore, environmental sustainability demands that society designs activities to meet human needs while indefinitely preserving the life support systems of the planet.

On the other hand, positive momentum creating for elevating climate change can be realized by the corporate governance priority [5]. Especially, including power, oil and gas, coal, air transportation and food products should be driven by this concept. It requires that leaders of corporate governance deliver short-term financial returns for the challenges that climate change presents in the long term.

\footnotetext{
${ }^{*}$ corresponding author; e-mail: beril@itu.edu.tr
}

Sustainability is important for the liveable earth. As known that: "Sustainable development is development that meets the needs of the present without compromising the ability of future generations to meet their own needs." [6]. Sustainable energy is a concept for application of energy systems. Sustainable energy is important for the welfare of the countries. Therefore sustainable energy related to economic growth, environment and social equity simultaneously is vital for our earth [7]. Figure 1 represents energy sustainability in the total sustainability concept [8].

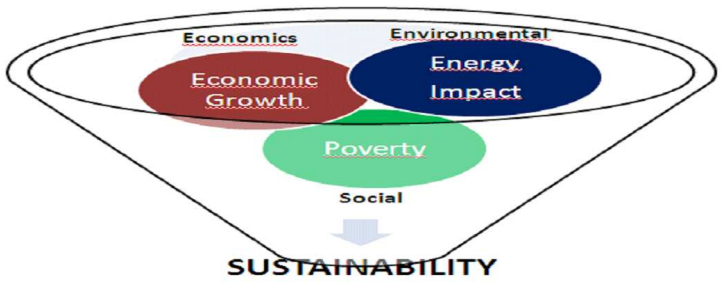

Fig. 1. Energy sustainability in the total sustainability concept.

\section{Importance of governance and corporate governance}

Global knowledge can be realized on the basis of different institutional and organizational arrangements such as public institutes, the private association of firms or private-public partnerships. The relationship between local industrial and global value chains can be structured into different institutional frameworks and regulated on the basis of different corporate governance models. Being linked to global value chains represents a learning opportunity that enterprises in developing countries can exploit to upgrade their capabilities.

The possibility for realizing specific macro policy goals hinges on their capacity affected by corporate governance 
in the information age. This procedure is very important for all countries in the name of sustainable development. It can be said that capacity and readiness influence countries' structural trajectories and underlying production and technological capabilities directly connecting with corporate governance [9]. Comparison of governance and corporate governance can be seen in Fig. 2.

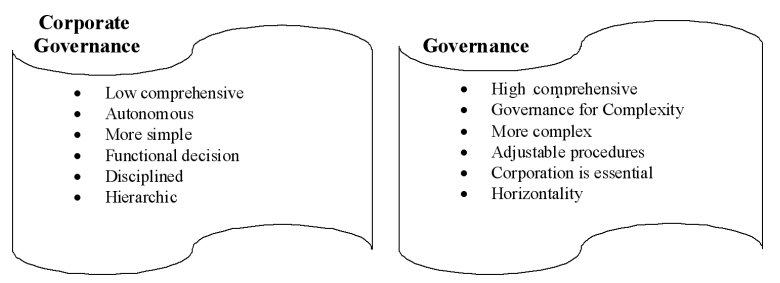

Fig. 2. Comparison of governance and corporate governance.

Energy needs stimulate new developments. It should be applied by organizational and systematic activities, but it has feedback effects which can be harmful for the sustainability concepts. Therefore, the corporate governance is also important for energy applications and affected by global warming.

\section{SWOT analysis}

SWOT analysis is a tool in order to appraise the strengths, weaknesses, opportunities and threats in a project or decision making with a strategic approach. It includes determining the goal of the project or decision making with diagnosing the internal and external factors which are supportive and unsupportive to succeeding that goal [10]. To achieve an effective SWOT analysis and get competitive benefits of each category (strengths, weaknesses, opportunities and threats) users have to ask and answer meaning questions [11]. Considering the facts of corporate governance for energy SWOT analysis table can be seen in Table I.

TABLE I

SWOT analysis table of corporate governance for energy.

\begin{tabular}{|c|c|}
\hline Strengths & Weaknesses \\
\hline Supporting by community (S1) & $\begin{array}{l}\text { Energy lack no permit to orga- } \\
\text { nize the corporate governance } \\
\text { (W1) }\end{array}$ \\
\hline International applicability (S2) & Political preferences (W2) \\
\hline Support the sustainability (S3) & $\begin{array}{l}\text { Hardness for adjustability } \\
\text { (W3) }\end{array}$ \\
\hline Opportunities & Threats \\
\hline $\begin{array}{l}\text { Increasing the conscious for } \\
\text { sustainability (O1) }\end{array}$ & $\begin{array}{l}\text { Regional energy crises and con- } \\
\text { flicts (T1) }\end{array}$ \\
\hline $\begin{array}{l}\text { International agreement re- } \\
\text { lated with sustainability \& } \\
\text { global warming (O2) }\end{array}$ & $\begin{array}{l}\text { Risks for energy supply secu- } \\
\text { rity (T2) }\end{array}$ \\
\hline High comprehension(O3) & $\begin{array}{l}\text { Rising trend of energy prices } \\
\text { (T3) }\end{array}$ \\
\hline
\end{tabular}

Main key information can be taken from internal and external analysis. Strengths or weaknesses of the corporate governance for energy depending upon their effect can be determined by own objectives that is internal analysis. Similarly, opportunities and threats evaluation represents as external analysis for the corporate governance for energy via SWOT matrix in Table I.

Use of conventional SWOT analysis bases on qualitative analysis and has no means of determining the importance of each SWOT factors. For this reason, an advance application was applied in the SWOT analysis that has been proposed weighting and rating individual SWOT factors using the pairwise comparison matrices [12]. Therefore, analytic hierarchy process (AHP) was applied for the quantitative SWOT analysis.

TABLE II

Weight values of SWOT analysis factors.

\begin{tabular}{c|c|c|c|c|c|c|c|c|c|c|c|c}
\hline \hline $\begin{array}{c}\text { SWOT } \\
\text { arguments }\end{array}$ & $\mathrm{S} 1$ & $\mathrm{~S} 2$ & $\mathrm{~S} 3$ & $\mathrm{~W} 1$ & $\mathrm{~W} 2$ & $\mathrm{~W} 3$ & $\mathrm{O} 1$ & $\mathrm{O} 2$ & $\mathrm{O} 3$ & $\mathrm{~T} 1$ & $\mathrm{~T} 2$ & $\mathrm{~T} 3$ \\
\hline weights & 8.0 & 7.0 & 8.5 & 9.0 & 9.0 & 8.5 & 7.0 & 7.0 & 7.0 & 9.5 & 8.5 & 8.0
\end{tabular}

Analytic hierarchy process is a multi-criteria decision making technique which decomposes the problem into a system of hierarchies, whereas the statistical assessment - linear alignment technique sorts the compared arguments by their scores and yields the best result by choosing the argument with the highest score. AHP is a structured technique for organizing and analyzing complex decisions based on mathematics that was applied in the study. It provides a comprehensive and rational framework for structuring a decision problem, for representing and quantifying its elements, for relating those elements to overall goals, and for evaluating alternative solutions. The AHP converts these evaluations to numerical values that can be processed and compared over the entire range of the problem. A numerical weight or priority is derived for each element of the hierarchy [13]. The weight values of SWOT analysis factors in Table I are given in Table II.

The priority value is given to those characteristics and is applied of SWOT analytical method. AHP matrix was created with the AHP application. This matrix is normalized and ultimately reached a preference matrix. These numbers represent the alternatives' relative ability to achieve the decision goal.

\section{Results and discussion}

Firstly, evaluation of SWOT analysis is realized by internal and external analysis for the corporate governance. As the internal analysis via SWOT matrix it is determined that:

- Energy lack does not permit to organize the corporate governance in spite of supporting by community;

- Political preferences are important factors for international applicability; 
- Hardness for adjustability should be solving via supporting sustainability for corporate governance.

As the external analysis via SWOT matrix it is determined that:

- Regional energy crisis and conflicts should be solved by increase of consciousness for sustainability;

- Risks for energy supply security drive international agreement for sustainability and climate change;

- Rising trend of energy prices should be evaluated with high comprehensive for corporate governance.

For the "quantitative SWOT analysis", "AHP matrix" was established according to weight values in Table I and normalized and determined the "priority matrix" for each element of the hierarchy. Priority values can be seen in Table III.

TABLE III

Priority values of SWOT analysis factors.

\begin{tabular}{c|c|c|c|c|c|c|c|c|c|c|c|c}
\hline \hline $\begin{array}{c}\text { SWOT } \\
\text { arguments }\end{array}$ & $\mathrm{S} 1$ & $\mathrm{~S} 2$ & $\mathrm{~S} 3$ & $\mathrm{~W} 1$ & $\mathrm{~W} 2$ & $\mathrm{~W} 3$ & $\mathrm{O} 1$ & $\mathrm{O} 2$ & $\mathrm{O} 3$ & $\mathrm{~T} 1$ & $\mathrm{~T} 2$ & $\mathrm{~T} 3$ \\
\hline $\begin{array}{c}\text { priority } \\
\text { values [\%] }\end{array}$ & 8.32 & 9.51 & 7.83 & 7.40 & 7.40 & 7.83 & 9.51 & 9.51 & 9.51 & 7.01 & 7.83 & 8.32
\end{tabular}

After the quantitative SWOT analysis, it is understood that the factors on

- International applicability,

- Increasing the consciousness for sustainability,

- International agreement for sustainability,

- High comprehension

have the strategic importance for the corporate governance for energy.

\section{Conclusion}

Corporate governance and related activities are important that broadly refers to the mechanisms, processes and relations by which corporations are controlled and directed especially for energy and energy supply security. Important factors for corporate governance energy management with the incorporated body environment can be evaluated by SWOT analysis and also quantitative SWOT analysis via applying AHP.
With the study, the main strategic objectives can be determined clearly by internal and external analysis with SWOT analysis. In the results of quantitative SWOT analysis, rising trend of energy prices with high comprehension causes the risks for energy supply and also causes the regional energy crisis and conflicts, but they can be solved by increasing consciousness and drive international agreement with the sustainability concept and related with global warming.

\section{References}

[1] A.B. Tugrul, J. En. Power Eng. 5, 905 (2011).

[2] A.B. Tugrul, "Decision Making Process in Energy Policies", YTU PSIR Bulletin, Summer 2015, p. 10.

[3] A.B. Tugrul, in: Proc. Int. Conf. on Energy Environmental Engineering - ICEEE 2014, Paris (France), World Academy of Science Engineering and Technology, 2014, p. 801.

[4] A.B. Tugrul, S. Çimen, 2013, in: Proc. Int. Conf. on Economics and Econometrics - ICEE 2013, Dubai (BAE), 2013, p. 40.

[5] D.C. Cogan, Corporate Governance and Climate Change: Making the Connection, Ceres, Boston 2006.

[6] WCED-1987, World Commission on Environment and Development, 1987: Our Common Future.

[7] M.L. Soriano, Energy-Integrated Planning for Low Carbon Development in Cities, UNDP, 2012.

[8] A.B. Tugrul, S. Cimen, Assessment of Sustainable Energy Development, Energy Systems and Management, Springer, Heidelberg 2015, p. 109.

[9] S. Fitzpatrick, Int. J. Product. Econ. 75, 98 (2002).

[10] B. Engin, A.B. Tugrul, J. En. Power Eng. 8, 1237 (2014).

[11] S. Abdurahman, A.B. Tugrul, IBU J. Sci. Technol. (IBUJST) 2, 195 (2014).

[12] H. Shinno, H. Yoshioka, S. Marpaung, S. Hachiga, J. Eng. Des. 17, 251 (2006).

[13] T.L. Saaty, K. Peniwati, GroupDecision Making: Drawing out and Reconciling Differences, RWS Publ., Pittsburgh, Pennsylvania 2008. 